30 INDIANA GEOLOGICAL INDIANA UNIVERSITY

\title{
PETROFACIES AND RESIDUAL SATURATION IN A CAMBRIAN-ORDOVICIAN CARBONATE RESERVOIR FOR GEOLOGICAL SEQUESTRATION USING MERCURY POROSIMETRY
}

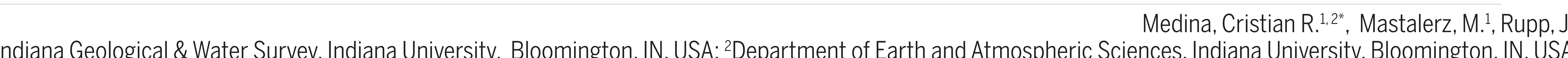

ABSTRACT

To better understand injection and post-injection flow processes and the entrapment of supercritical $\mathrm{CO}_{2}$ cenger in sixty-six Cambrian-Ordovician carbonate samples from multiple states in the midwestern United States.

This work employed standard microphotography from thin sections, helium porosimetry for porosity and permeability, and mercury injection capillary pressure analysis, aliming to understand which elements of the pore system dominantly control the overall flow and $\mathrm{CO}_{2}$ storage potential in the subsurface.

This work analyzes mercury injection capiliary pressure data and proposes a petrophysical subdivision of he samples into four petrofaces, which is based on hier values of porosity, perneability, and capillary entry pressure. This system aims to predict the portions of the studied carbonate sequence that are pre permeability, capillary entry pressure, and pore size all play a role in ensuring both buoyant and capillary

Results from this investigation suggest that in these Cambrian-Ordovician carbonate reservoirs, pore size inversely correlates with capillary entry pressure, and that permeability does not always hold a direct pore system.

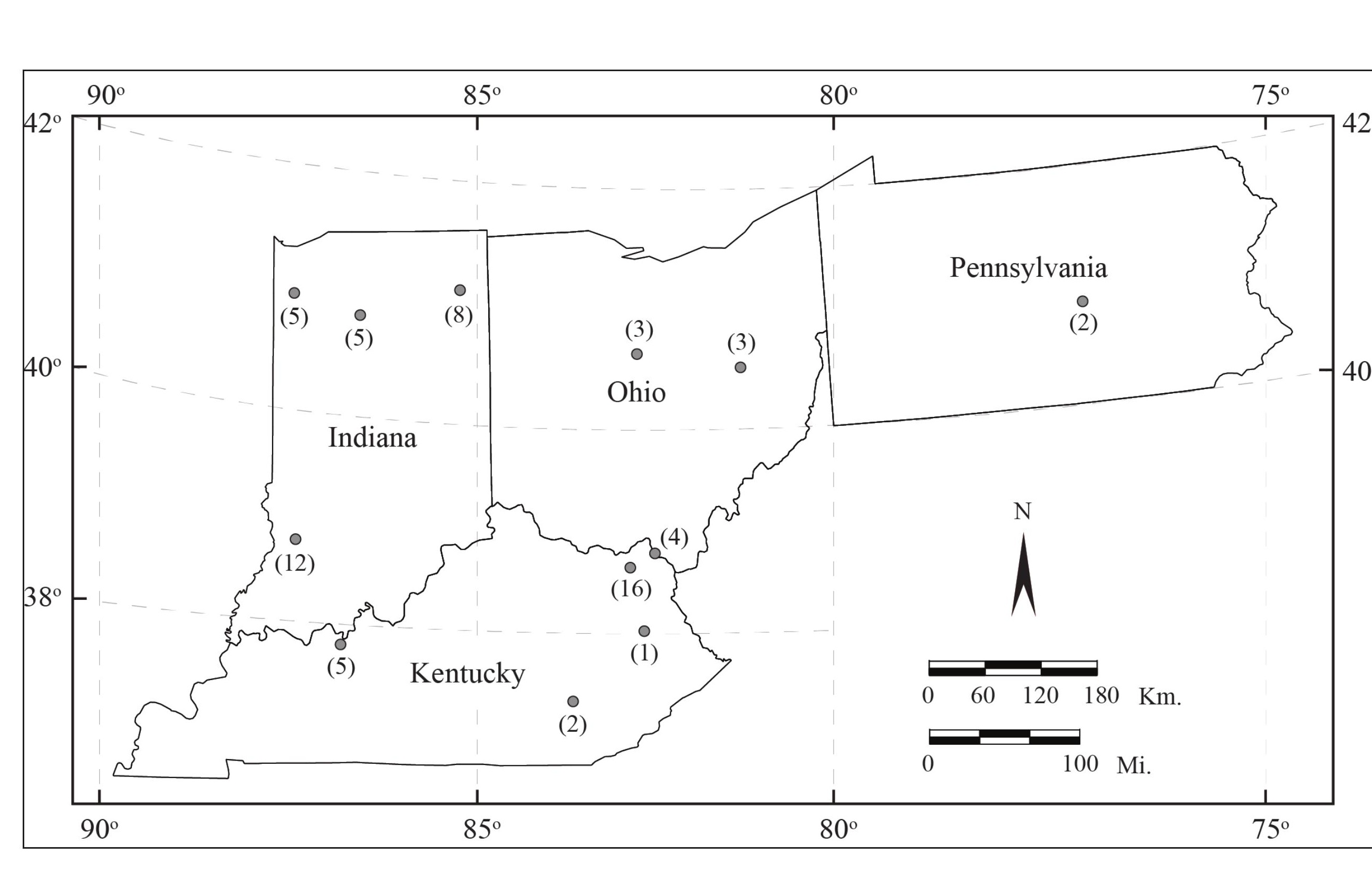

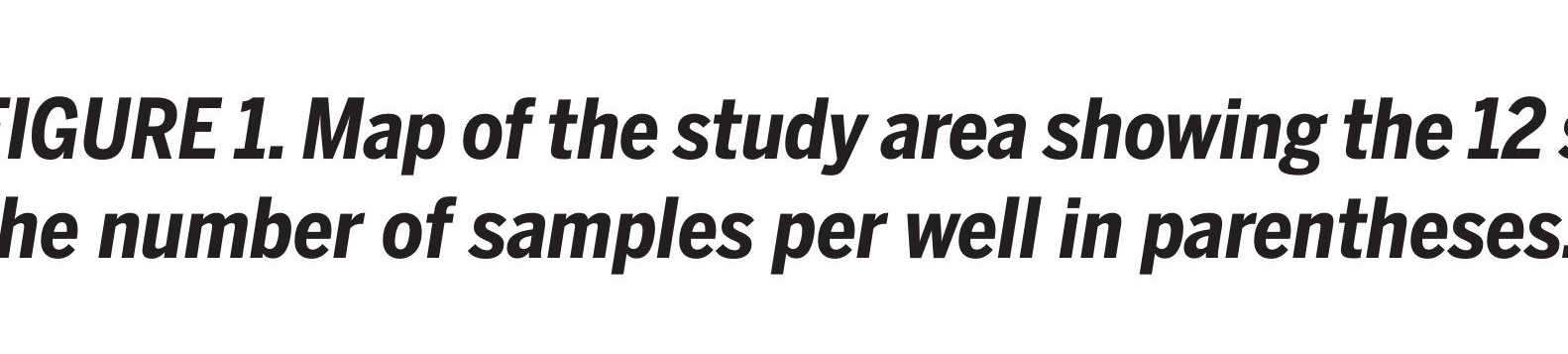

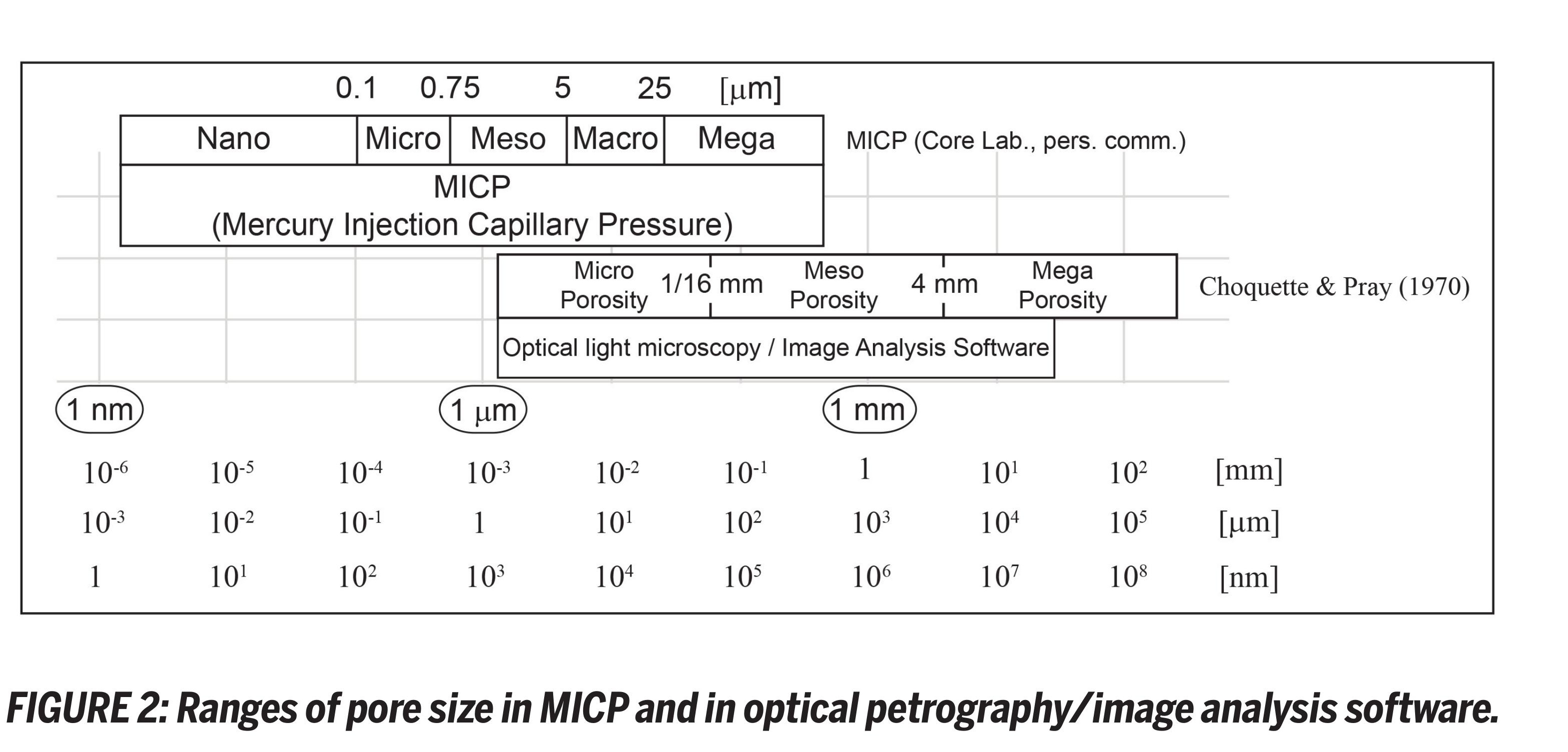

1 WHAT AND WHY: INTRODUCTION AND PURPOSE

Deep and widespread saline aquifers, such as those that occur in the Knox Supergroup in the midwestern region of the United States, offer suitable targets for $\mathrm{CO}_{2}$ sequestration

- The purpose of this paper is to evaluate the relationships between porosity and permeability and pore size distribution.

- This work aligns with one of the primary goals of the Midwest Regional Carbon Sequestration Partnership to characterize and quantify the amount of resources (pore space) in saline aquifers for the geologic storage of carbon dioxide.

\section{SAMPLES AND METHODOLOGY}

- Studies of and comparison among techniques, such as image analysis from thin section, mercury injection capillary pressure tests (MICP) will help us understand the role and relative contribution to geologic storage of $\mathrm{CO}_{2}$ provided by macro-, meso-, and microporosity (Fig. 2).
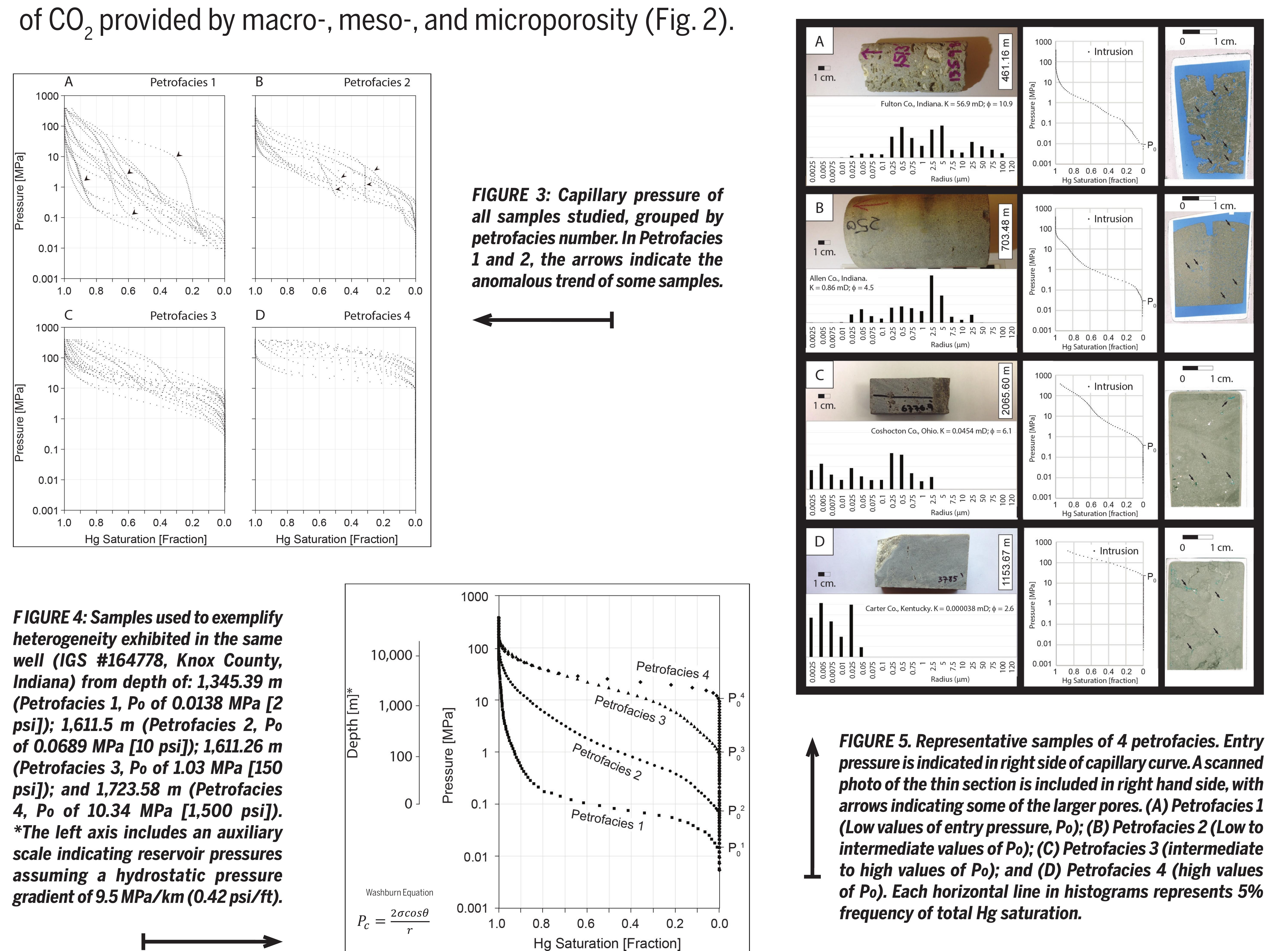

3 RESULTS

- Each one of these groups al

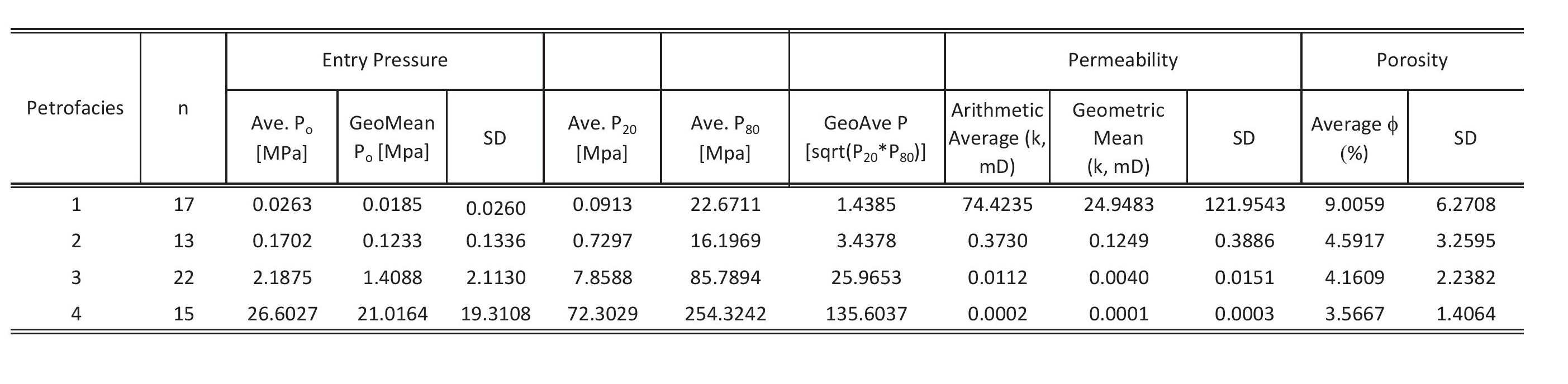

.

- There is a clear distinction between larger-pore-dominated samples (higher porosity and permeability) and
smaller-pore-dominated sample (i.e. Fig. 5 A vs. Fig. 5 D).

- This method (MICP) results in a log-normal saturation curve (mercury injection curve, Figs. 3, 4, 5, and 1) that be transformed to a pore size.
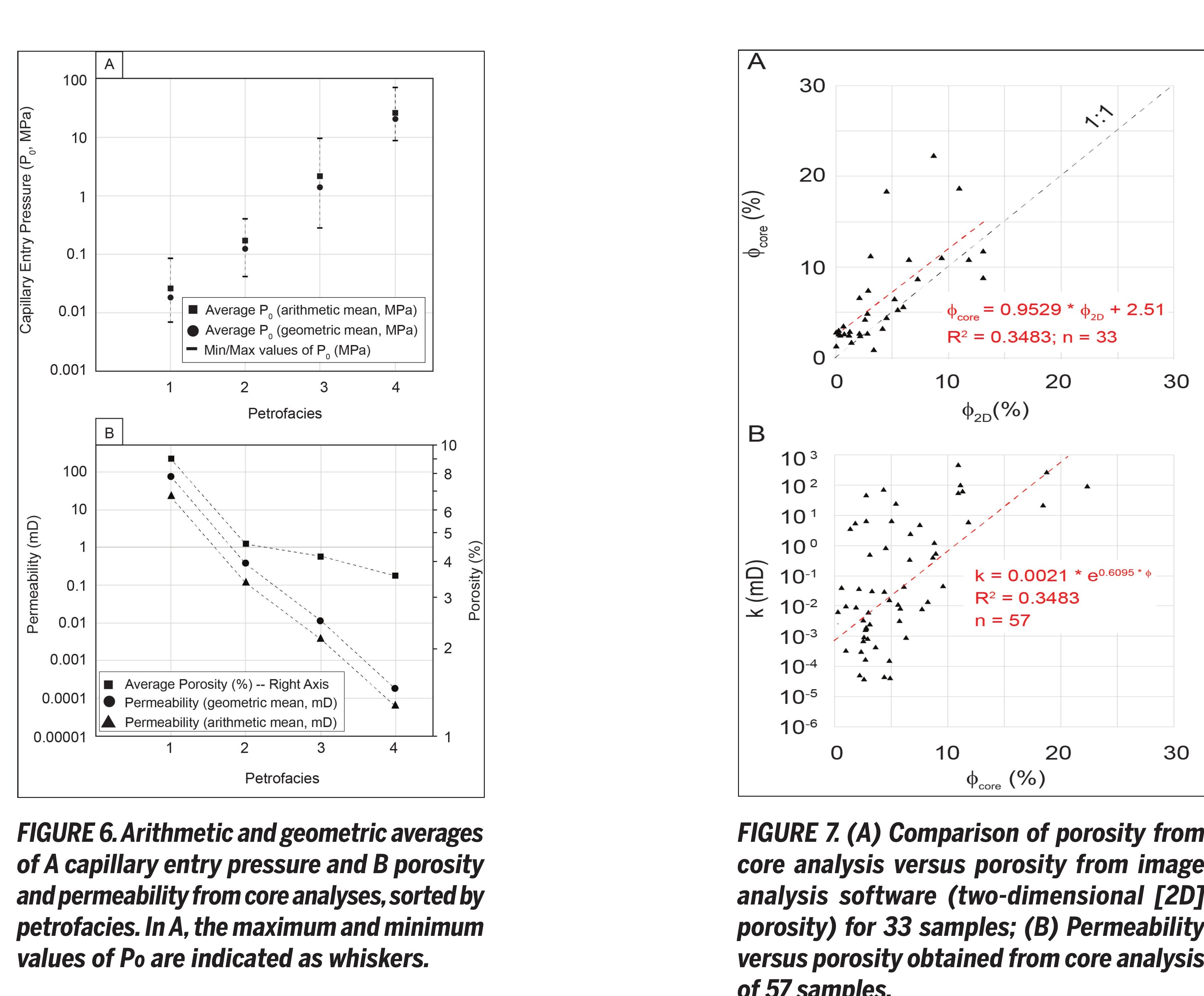

crmedina@indiana.edu

4 CONCLUSIONS

Samples from the Knox Supergroup exhibit pore sizes that span several orders of magnitude. Pore-size distribution (Fig. 10) and pore connectivity (Fig. 11) seem to have a direct influence on permeability (Figs. 9-11)
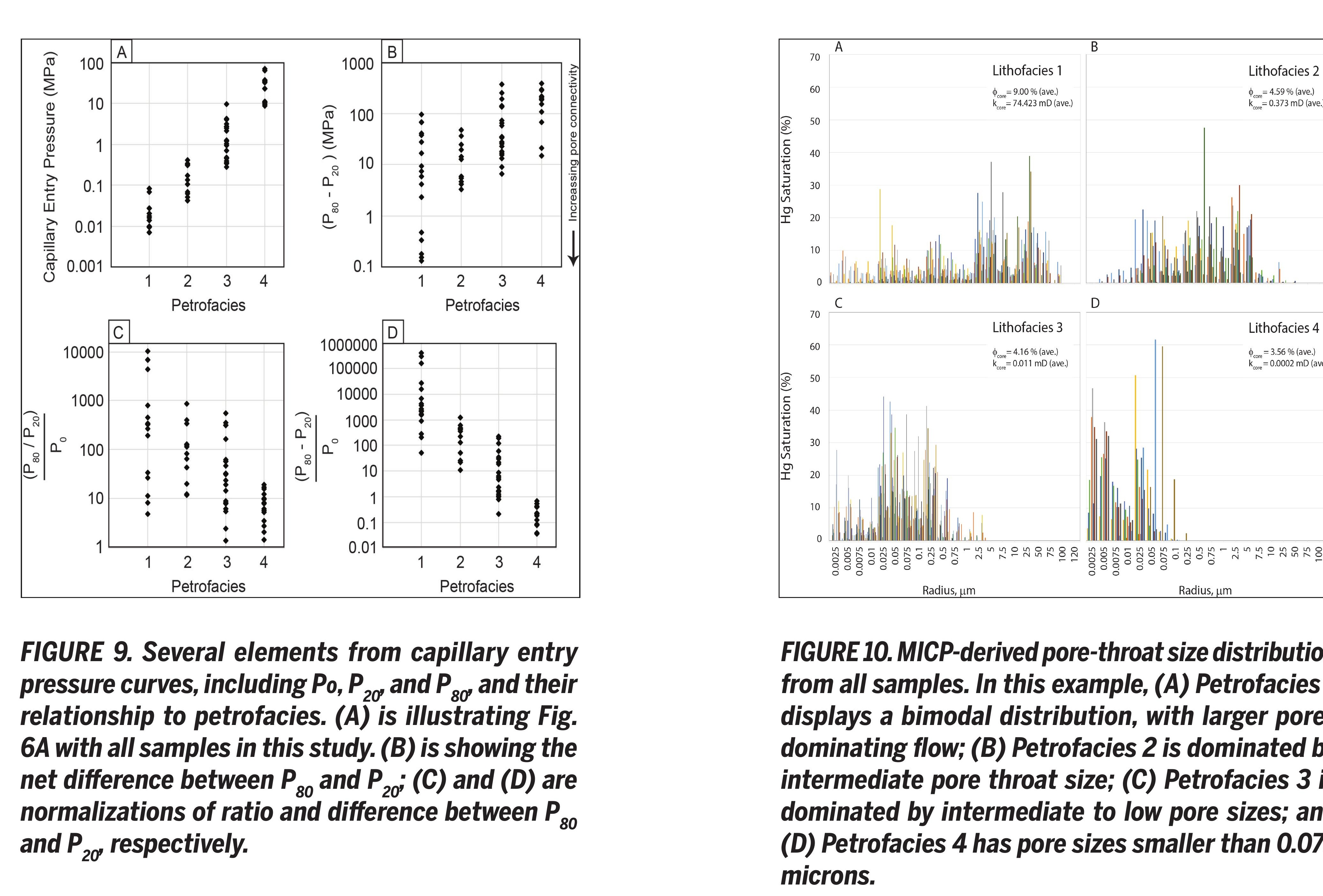

5 ACKNOWLEDGMENTS

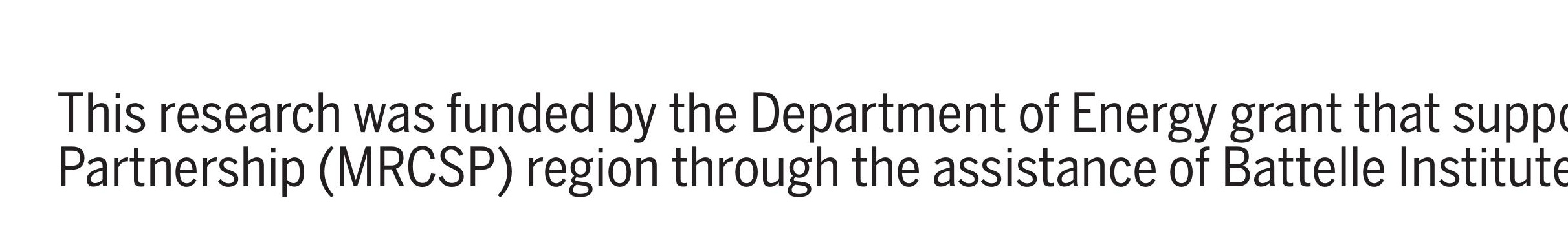
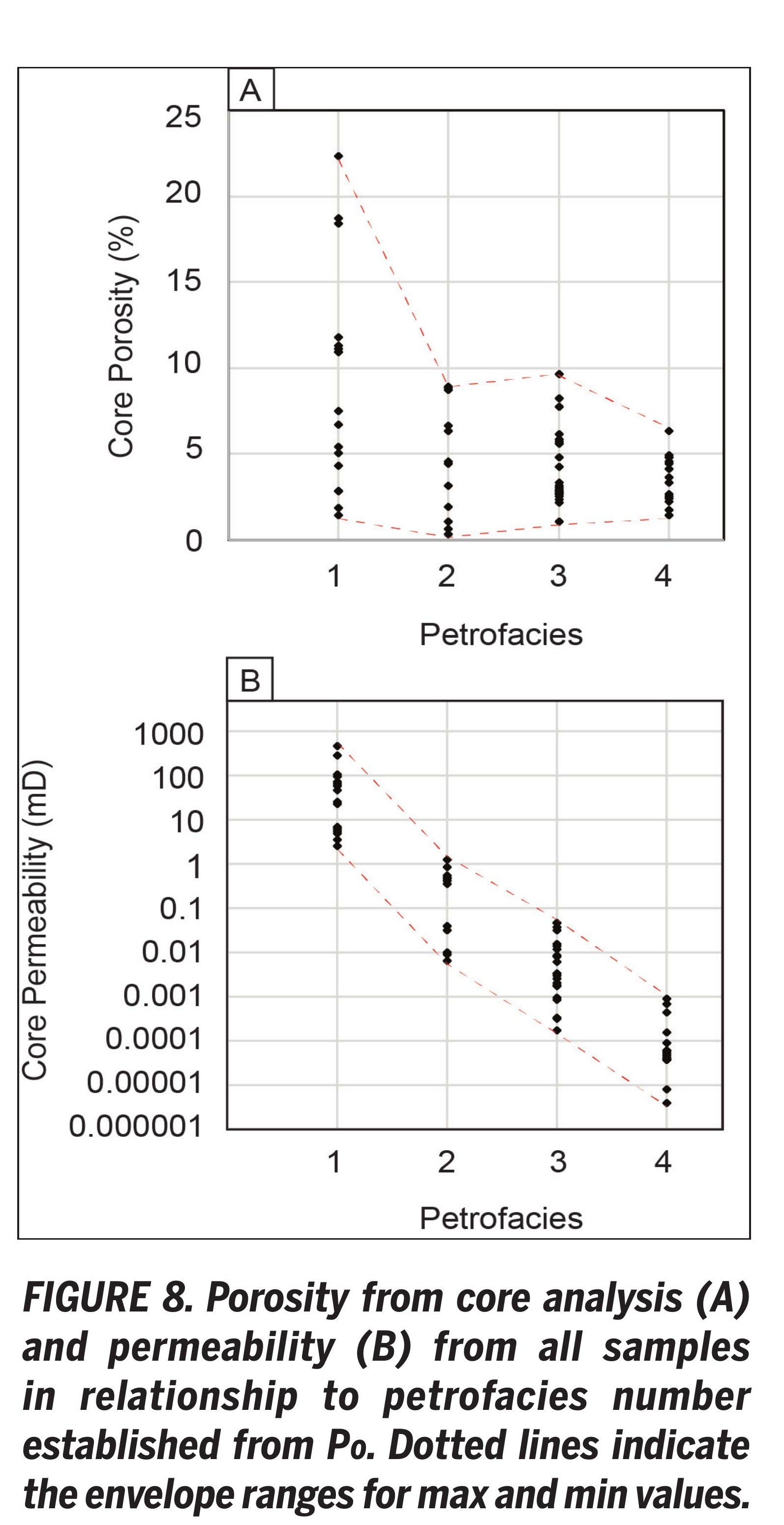